\title{
Association of ADAM33 gene polymorphisms with adult allergic asthma and rhinitis in a Chinese Han population Dongju Su ${ }^{\dagger 1}$, Ximei Zhang ${ }^{\dagger 2}$, Hong Sui ${ }^{3}$, Fuzhen Lü*1, Lianhong Jin*2 and Jing Zhang1
}

Address: ${ }^{1}$ Department of Respiratory, The Second Affiliated Hospital of Harbin Medical University, Harbin 150086, PR China, ${ }^{2}$ Department of Histology and Embryology, Harbin Medical University, Harbin 150086, PR China and ${ }^{3}$ Department of Statistics, Harbin Medical University, Harbin 150086, PR China

Email: Dongju Su - sudongju@yahoo.com.cn; Ximei Zhang - ximei1119@yahoo.com.cn; Hong Sui - suisuihong@126.com; Fuzhen Lü* - yyhhww@yahoo.com.cn; Lianhong Jin* - zx2005@yahoo.cn; Jing Zhang - m88512@sina.com

* Corresponding authors †Equal contributors

Published: 9 September 2008

BMC Medical Genetics 2008, 9:82 doi:10.1 186/147I-2350-9-82
Received: 15 May 2008

Accepted: 9 September 2008

This article is available from: http://www.biomedcentral.com/I47I-2350/9/82

(c) 2008 Su et al; licensee BioMed Central Ltd.

This is an Open Access article distributed under the terms of the Creative Commons Attribution License (http://creativecommons.org/licenses/by/2.0), which permits unrestricted use, distribution, and reproduction in any medium, provided the original work is properly cited.

\begin{abstract}
Background: Rhinitis and asthma are very common diseases involving genetic and environmental factors. Most patients with asthma also have rhinitis, which suggests the concept of 'one airway, one disease.' A disintegrin and metalloproteinase 33 (ADAM33) is the first asthma-susceptible gene to be discovered by positional cloning. To evaluate the potential influence of ADAM33 gene polymorphisms on allergic rhinitis (AR) and allergic asthma (AS), a case-control study was conducted on the Han population of northeast China.
\end{abstract}

Methods: Six polymorphic sites ( $\mathrm{V} 4, \mathrm{~T}+\mathrm{I}, \mathrm{T} 2, \mathrm{TI}, \mathrm{SI}$, and $\mathrm{Q}-\mathrm{I})$ were genotyped in 128 patients with AR, I8I patients with AS, and I5I healthy controls (CTR). Genotypes were determined by the polymerase chain restriction fragment length polymorphism (PCR-RFLP) method. Data were analyzed using the chi-square test with Haploview software.

Results: The single nucleotide polymorphisms (SNPs), $V 4 G / C, T+I A / G$, and $T I G / A$, of the ADAM33 gene may be the causal variants in AR, whereas ADAM33 V4 G/C, T2 A/G, TI G/A, and Q-IA/G may participate in the susceptibility of AS.

Conclusion: These results suggest that polymorphisms of the ADAM33 gene may modify individual susceptibility to AR and AS in a Chinese Han population.

\section{Background}

Rhinitis is defined as inflammation of the nasal mucosa and is characterised by nasal discharge, blockage, sneezing, and itching $[1,2]$. Asthma is a chronic inflammatory disorder of the airway which causes recurrent episodes of wheezing, breathlessness, chest tightness, and coughing in susceptible individuals. These episodes are usually associated with widespread, but variable airflow obstruc- tion that is often reversible, either spontaneously or with treatment. The inflammation also causes an associated increase in existing bronchial hyper-responsiveness (BHR) to a variety of stimuli $[1,2]$. Epidemiologic studies have consistently shown that asthma and rhinitis often coexist in the same patients in every region of the world [3-5], suggesting the concept of 'one airway, one disease.' The basic premise is that rhinitis and asthma represent the 
manifestations of one syndrome in two parts of the respiratory tract [6]. In order to raise awareness of the theory of 'one airway, one disease,' the Allergic Rhinitis and Its Impact on Asthma (ARIA) Workshop Group publication proposes three considerations for patients with allergic respiratory disease [7].

ADAM33 is the first reported asthma-susceptible gene identified by positional cloning [8]. ADAM33 is a complex molecule, the expression of which is largely restricted to mesenchymal cells, including fibroblasts and smooth muscle cells, and codes for a protein important for cell fusion, cell adhesion, cell signalling, and proteolysis [9]. The ADAM33 gene is located on chromosome 20p13 and 37 single nucleotide polymorphisms (SNPs) have initially been identified [8]. Recently, several SNPs in the ADAM33 gene have been shown to be significantly associated with asthma, BHR, and atopy [10]. Taken together, these findings suggest an important role for ADAM33 in airway remodelling and asthma [8]. To date, most data available for ADAM33 and asthma have been obtained from Caucasians, but few data on ADAM33 SNPs associated with asthma and atopic disease are available for Asian populations [11-14]. The aim of the present study was to determine whether ADAM33 SNPs are associated with allergic rhinitis (AR) and allergic asthma (AS) in a Chinese Han population.

\section{Methods \\ Subjects}

The study group consisted of 128 Chinese patients with AR, 181 patients with AS, and 151 healthy controls (CTR). They were recruited from The 2nd Clinical College of Harbin Medical University in China. The characteristics of the study population are shown in Table 1 . The diagnosis of AR was made on the basis of the criteria of the Chinese Society of Allergology (2003). Patients had to satisfy the following AR criteria for inclusion: (1) nasal discharge, blockage, and sneezing, with the 3 symptoms occurring for more than 30 minutes on most days and for more than 6 months per year and (2) persistent symptoms for at least 1 year. AS was diagnosed according to the criteria of the Chinese Society of Allergology (2003). Patients had to satisfy the following AS criteria for inclusion: (1) continual episodes of wheezing and dyspnea which require therapy, (2) clinically-diagnosed wheezing, (3) reversible airway

Table I: Description of study population

\begin{tabular}{cccc}
\hline Characteristic & AR & AS & CTR \\
\hline Number of patients & I28 & I8। & I5। \\
Age (years) & $39.27 \pm 13.53$ & $36.69 \pm 11.53$ & $37.18 \pm 10.60$ \\
Gender (Female) & $44(34.38 \%)$ & $67(37.02 \%)$ & $54(35.76 \%)$ \\
FEVI (\%) & $100.95 \pm 5.36$ & $73.38 \pm 10.66$ & $102.84 \pm 3.1 \mathrm{I}$
\end{tabular}

obstruction shown by $>15 \%$ variation in daily values of volume in the $1^{\text {st }}$ second of forced expiration (FEV1) and peak expiratory flow (PEF) after inhalation or administration of a bronchodilator, and (4) elevated levels of serum total IgE with at least one type of allergen-specific IgE. One hundred fifty-one unrelated healthy Chinese Han adults with no history of asthma and rhinitis were designated as CTR patients. Both patients and the healthy CTR were recruited from the Heilongjiang Province of China between August 2006 and June 2007. The present study was approved by the Ethics Committee of the Harbin Medical University and adhered to the tenets of the Helsinki Declaration. Additionally, the written informed consent was obtained from the patients.

\section{DNA extraction and genotyping}

Genomic DNA was extracted from $5 \mathrm{ml}$ of frozen whole blood using a DNA Extraction Kit (Qiagen, Germany), according to the manufacturer's protocol and following the manufacturers' instructions. We selected 6 SNPs in the ADAM33 gene, which previously had been shown to have an allelic and/or haplotype association with AS, including V4(rs2787094), T+1(rs2280089), T2(rs2280090), T1(rs2280091), S1(rs3918396), and Q-1(rs612709). Using the unique rs accession numbers, SNP details and sequence data are available through NCBI databases http:/ /www.ncbi.nlm.nih.gov. The polymorphic region was amplified by PCR with a TGradient Thermoblock PCR System (Iometra, Germany) in a $25 \mu \mathrm{l}$ reaction solution containing $0.3 \mu \mathrm{g}$ genomic DNA, $1 \times$ PCR buffer, $0.3 \mathrm{mM}$ $\mathrm{MgCl}_{2}, 0.2 \mathrm{mM}$ dNTPs, $2 \mathrm{U}$ TaqDNA polymerase (Takara, Japan), and $0.1 \mu \mathrm{mol}$ of each primer (Invitrogen, USA). Genotyping primers and PCR programs are shown in Table 2. PCR products were digested overnight with restriction enzymes (NEB, UK), according to the manufacturer's protocol, and analyzed by $2 \%$ agarose gel electrophoresis. The restriction enzymes and the length of the digested fragments are shown in Table 3.

\section{Statistical analyses}

We tested for the Hardy-Weinberg equilibrium (HWE) among cases and controls separately. The genotype and allele frequencies were obtained by direct counting. Statistical significance was defined as a $\mathrm{P}<0.05$. In order to obtain a measure of significance corrected for multiple testing bias, we ran 10,000 permutations to compute Pvalues using the Haploview program. Comparisons of the distributions of the allele and genotype frequencies were performed using the chi-square test. The relative risk associated with rare alleles was estimated as an odds ratio (OR) with a $95 \%$ confidence interval (CI).

\section{Results}

The genotype and allele frequencies of the ADAM33 gene polymorphisms in patients and healthy controls are 
Table 2: Primers and PCR programs for ADAM33 PCR-RFLP genotyping

\begin{tabular}{|c|c|c|c|}
\hline Reference SNP ID & Gene/SNP primer & Sequence & PCR program \\
\hline \multirow[t]{2}{*}{ rs2787094 } & ADAM33 V4C/G F & 5'-ACACACAGAATGGGGGAGAG-3' & $94^{\circ} \mathrm{C} 5 \mathrm{~min} ; 35$ cycles, $94^{\circ} \mathrm{C} 30 \mathrm{~s}$, \\
\hline & ADAM33 V4C/G R & 5'-CCAGAAGCAAAGGTCACACA-3' & $53^{\circ} \mathrm{C} 30 \mathrm{~s}, 72^{\circ} \mathrm{C} 30 \mathrm{~s} ; 72^{\circ} \mathrm{C} 5 \mathrm{~min}$ \\
\hline \multirow[t]{2}{*}{ rs2280089 } & ADAM33T+IA/G F & 5'-CTGAGCCCAGAAACCTGATT-3' & $94^{\circ} \mathrm{C} 5 \mathrm{~min} ; 35$ cycles, $94^{\circ} \mathrm{C} 30 \mathrm{~s}$, \\
\hline & ADAM33T+IA/G R & 5'-AGAAGGGAAGGGCTCATGC-3' & $54^{\circ} \mathrm{C} 30 \mathrm{~s}, 72^{\circ} \mathrm{C} 30 \mathrm{~s} ; 72^{\circ} \mathrm{C} 5 \mathrm{~min}$ \\
\hline \multirow[t]{2}{*}{ rs2280090 } & ADAM33 T2A/G F & 5'-TTCTCAGGGTCTGGGAGAAA-3' & $94^{\circ} \mathrm{C} 5 \mathrm{~min} ; 35$ cycles, $94^{\circ} \mathrm{C} 30 \mathrm{~s}$, \\
\hline & ADAM33 T2A/G R & 5'-GCCAACCTCCTGGACTCTTA-3' & $52^{\circ} \mathrm{C} 30 \mathrm{~s}, 72^{\circ} \mathrm{C} 30 \mathrm{~s} ; 72^{\circ} \mathrm{C} 5 \mathrm{~min}$ \\
\hline \multirow[t]{2}{*}{ rs2280091 } & ADAM33 TIA/G F & 5'-ACTCAAGGTGACTGGGTGCT-3' & $94^{\circ} \mathrm{C} 5 \mathrm{~min} ; 35$ cycles, $94^{\circ} \mathrm{C} 30 \mathrm{~s}$, \\
\hline & ADAM33 TIA/G R & 5'-GAGGGCATGAGGCTCACTTG-3' & $54^{\circ} \mathrm{C} 30 \mathrm{~s}, 72^{\circ} \mathrm{C} 30 \mathrm{~s} ; 72^{\circ} \mathrm{C} 5 \mathrm{~min}$ \\
\hline \multirow[t]{2}{*}{ rs3918396 } & ADAM33 SIA/G F & 5'-TGTGCAGGCTGAAAGTATGC-3' & $94^{\circ} \mathrm{C} 5 \mathrm{~min} ; 35 \mathrm{cycles}, 94^{\circ} \mathrm{C} 30 \mathrm{~s}$, \\
\hline & ADAM33 SIA/G R & 5'-AGAGCTCTGAGGAGGGGAAC-3' & $50^{\circ} \mathrm{C} 30 \mathrm{~s}, 72^{\circ} \mathrm{C} 30 \mathrm{~s} ; 72^{\circ} \mathrm{C} 5 \mathrm{~min}$ \\
\hline \multirow[t]{2}{*}{ rs612709 } & ADAM33 Q-IA/G F & 5'-GGATTCAAACGGCAAGGAG-3' & $94^{\circ} \mathrm{C} 5 \mathrm{~min} ; 35$ cycles, $94^{\circ} \mathrm{C} 30 \mathrm{~s}$, \\
\hline & ADAM33 Q-IA/G R & 5'-GTTCACCTAGATGGCCAGGA-3' & $60^{\circ} \mathrm{C} 30 \mathrm{~s}, 72^{\circ} \mathrm{C} 30 \mathrm{~s} ; 72^{\circ} \mathrm{C} 5 \mathrm{~min}$ \\
\hline
\end{tabular}

shown in Tables 4, 5 and 6 . All of the six SNPs genotyped were in HWE $(\mathrm{P}>0.05)$ in the case and control cohorts. The ADAM33 V4 G, T+1 A, and T1 G allele carrier frequencies were significantly higher in AR patients than in the CTR patients $(\mathrm{P}<0.0001,=0.0037$, and $<0.0001$, respectively). Statistical analysis revealed no significant differences in the allele frequencies in T2 A/G, S1 G/A, and Q-1 $\mathrm{A} / \mathrm{G}$ between AR and CTR patients. The differences at the $\mathrm{V} 4, \mathrm{~T} 2, \mathrm{~T} 1$, and Q-1 sites between the AS and CTR groups were significant $(\mathrm{P}<0.0001)$. In contrast, no significant differences in the allele frequency distribution at the $\mathrm{T}+1$ and $\mathrm{S} 1$ sites between the AS and CTR groups were observed. The ADAM33 V4 G, T2 A, T1 G, and Q-1 A allele frequencies were significantly higher in the AS patients than in the CTR patients $(\mathrm{P}<0.0001)$. Correction for multiple tests was performed in this study.

\section{Discussion}

The work by van Eerdewegh et al. [8] that identified ADAM33 as an asthma-susceptible gene using positional cloning and an association study had a profound impact on researchers investigating the genetics of bronchial asthma. Polymorphisms of ADAM33 were originally shown to be associated with BHR. In previous studies, T1, $\mathrm{T} 2, \mathrm{~S} 2$, and V-3 sites were reported in Japanese adult populations $[13,15]$, and these associations were also found in our samples. In contrast, no association was found between asthma and ADAM33 in Puerto Rican and Mexican populations [16], and a Korean population [12]. The study by van Eerdewegh [8] was the first to show that ADAM33 polymorphisms (Q-1, S1, ST+4, ST+7, V-1, and
V4) and haplotypes were associated with asthma in Caucasian families. Recently, Raby et al. [17] performed a family-based association study for childhood asthma and ADAM33 SNPs in 652 nuclear families. They showed that no single SNP was associated with childhood asthma in Caucasians, but that a common haplotype of ADAM33 was associated with the disease. They also reported that $\mathrm{T} 1$ and $\mathrm{T}+1$ were marginally associated with childhood asthma in Hispanics. In previous association studies of ADAM33 and asthma/asthma-associated phenotypes, no single ADAM33 SNP was consistently associated with asthma or intermediate phenotypes. This may be because of allelic heterogeneity, a single disorder caused by different mutations within a gene [14]. A number of studies have been conducted to replicate the original findings, some confirming and others refuting the association of ADAM33 with asthma [17-19]. In the present study, adult asthma was associated with ADAM33 SNPs, V4, T2, T1, and $\mathrm{Q}-1$, but not with the $\mathrm{T}+1$ and $\mathrm{S} 1$, and the $\mathrm{V} 4, \mathrm{~T}+1$, and $\mathrm{T} 1$ sites were also found to have significant associations with AR after correction for multiple tests. Comparison of our results with those studies indicates that no single SNP was universally associated with the asthma phenotype. The genetic basis of asthma may differ between different ethnic groups; it is possible that a particular subset of SNPs may be a risk factor for asthma in Caucasians, and that a different subset may increase the risk in Asian populations [13].

Epidemiological studies have clearly shown that rhinitis and asthma are frequently concurrent $[20,21]$. The major-

Table 3: Restriction enzymes and length of digested fragments

\begin{tabular}{ccccccc}
\hline & V4C/G & T+IA/G & T2A/G & TIA/G & SIA/G & Q-IA/G \\
\hline $\begin{array}{c}\text { Enzyme } \\
\text { Length of digested }\end{array}$ & Pstl & G: $168+206$ & A : $284+28$ & ApyCH4III & Ncol & Hinfl \\
fragments (bp) & C: 374 & G: 312 & G: 310 & A: $140+260$ & G: $132+172$ & A: $20+138$ \\
G: & & & A: 400 & G: 158 &
\end{tabular}


Table 4: Genotype frequency distribution and association study in ADAM33 between AR and CTR

\begin{tabular}{|c|c|c|c|c|c|}
\hline \multicolumn{2}{|c|}{ Genotype } & \multicolumn{2}{|c|}{ Frequency, no.(\%) } & \multirow[t]{2}{*}{$\mathrm{x}^{2} \mathrm{P}$ value } & \multirow{2}{*}{$\begin{array}{l}\text { Odds ratio } \\
(95 \% \mathrm{Cl})\end{array}$} \\
\hline & & $\operatorname{AR}(n=128)$ & $\operatorname{CTR}(n=|5|)$ & & \\
\hline \multirow[t]{3}{*}{ rs2787094 } & $\mathrm{CC}$ & $46(35.94)$ & II $3(74.84)$ & $<0.0001$ & $0.19(0.11-0.32)$ \\
\hline & CG & $60(46.88)$ & $32(21.19)$ & $<0.0001$ & $3.28(1.95-5.53)$ \\
\hline & GG & $22(17.18)$ & $6(3.97)$ & 0.0003 & $5.02(1.97-12.80)$ \\
\hline \multirow[t]{3}{*}{ rs2290089 } & AA & $4(3.13)$ & 0 & 0.0432 & \\
\hline & AG & $51(39.84)$ & $4 I(27.15)$ & 0.0246 & $1.78(1.07-2.94)$ \\
\hline & GG & $73(57.03)$ & $110(72.85)$ & 0.0056 & $0.49(0.30-0.82)$ \\
\hline \multirow[t]{3}{*}{ rs2280090 } & AA & 0 & 0 & & \\
\hline & $A G$ & $24(\mid 8.75)$ & $12(7.95)$ & 0.0073 & $2.67(1.28-5.59)$ \\
\hline & GG & $104(81.25)$ & $139(92.05)$ & 0.0073 & $0.37(0.18-0.78)$ \\
\hline \multirow[t]{3}{*}{ rs2280091 } & AA & $56(43.75)$ & $117(77.48)$ & $<0.0001$ & $0.23(0.13-0.38)$ \\
\hline & AG & $55(42.97)$ & $29(19.21)$ & $<0.0001$ & $3.17(1.86-5.41)$ \\
\hline & GG & $17(13.28)$ & $5(3.31)$ & 0.0021 & $4.47(1.60-12.49)$ \\
\hline \multirow[t]{3}{*}{ rs3918396 } & AA & $100(78.12)$ & $110(72.85)$ & 0.3086 & \\
\hline & AG & $28(21.88)$ & $4 I(27.15)$ & 0.3086 & \\
\hline & GG & 0 & 0 & & \\
\hline \multirow[t]{3}{*}{ rs612709 } & AA & 0 & 0 & & \\
\hline & $A G$ & $16(12.5)$ & II(7.28) & 0.142 & \\
\hline & GG & $112(87.5)$ & $140(92.72)$ & 0.142 & \\
\hline
\end{tabular}

ity of patients with AS also have AR, which presents in more than $75 \%$ of the patients with allergic asthma [22]. The relationship between AR and AS has become a focus of research. Recent advances have demonstrated that systemic inflammatory responses play a critical and integrating role in the pathophysiology of airway disease. Substantial evidence has also shown that AR and AS are closely linked, and the concept of 'one airway, one disease' has emerged [23]. Under this hypothesis, AS and AR are regarded as a combined entity of upper and lower airway disease influenced by the inflammatory process. An alteration of upper airway function could therefore affect the function of the lower airway. Improvement of AR symptoms is associated with resolution of AS symptoms. On the other hand, deterioration of AR symptoms may exacerbate AS symptoms. Consequently, appropriate management of AR could decrease the risk of AS developing or AS exacerbation [23]. The results of several epide-

Table 5: Genotype frequency distribution and association study in ADAM33 between AS and CTR

\begin{tabular}{|c|c|c|c|c|c|}
\hline \multicolumn{2}{|c|}{ Genotype } & \multicolumn{2}{|c|}{ Frequency, no.(\%) } & \multirow[t]{2}{*}{$x^{2} P$ value } & \multirow{2}{*}{$\begin{array}{l}\text { Odds ratio } \\
(95 \% \mathrm{Cl})\end{array}$} \\
\hline & & $A S(n=18 I)$ & $\operatorname{CTR}(n=151)$ & & \\
\hline \multirow[t]{3}{*}{ rs2787094 } & $\mathrm{CC}$ & $49(27.07)$ & $113(74.84)$ & $<0.0001$ & $0.12(0.08-0.20)$ \\
\hline & CG & $78(43.09)$ & $32(21.19)$ & $<0.0001$ & $2.82(1.73-4.59)$ \\
\hline & GG & $54(29.84)$ & $6(3.97)$ & $<0.0001$ & $10.28(4.28-24.69)$ \\
\hline \multirow[t]{3}{*}{ rs2290089 } & AA & 0 & 0 & & \\
\hline & $A G$ & $37(20.44)$ & $4 I(27.15)$ & 0.151 & \\
\hline & GG & $144(79.56)$ & $110(72.85)$ & 0.151 & \\
\hline \multirow[t]{3}{*}{ rs2280090 } & $A A$ & $4(2.21)$ & 0 & 0.1289 & \\
\hline & AG & $49(27.07)$ & I2(7.95) & $<0.0001$ & $4.30(2.19-8.44)$ \\
\hline & GG & $128(70.72)$ & $139(92.05)$ & $<0.0001$ & $0.21(0.11-0.4 I)$ \\
\hline \multirow[t]{3}{*}{ rs228009I } & $A A$ & $63(34.81)$ & $117(77.48)$ & $<0.0001$ & $0.16(0.10-0.25)$ \\
\hline & $A G$ & $78(43.09)$ & $29(19.21)$ & $<0.0001$ & $3.19(1.93-5.26)$ \\
\hline & GG & $40(22.10)$ & $5(3.31)$ & $<0.0001$ & $8.28(3.18-21.59)$ \\
\hline \multirow[t]{3}{*}{ rs3918396 } & AA & $140(77.35)$ & $110(72.85)$ & 0.3437 & \\
\hline & AG & $4 I(22.65)$ & $4 I(27.15)$ & 0.3437 & \\
\hline & GG & 0 & 0 & & \\
\hline \multirow[t]{3}{*}{ rs612709 } & AA & 0 & 0 & & \\
\hline & AG & $44(24.31)$ & II(7.28) & $<0.0001$ & $4.09(2.03-8.24)$ \\
\hline & GG & $137(75.69)$ & $140(92.72)$ & $<0.0001$ & $0.24(0.12-0.49)$ \\
\hline
\end{tabular}


Table 6: Allele frequency distribution and association study in ADAM33

\begin{tabular}{|c|c|c|c|c|c|c|c|c|c|c|}
\hline \multirow[t]{2}{*}{ Name } & \multirow[t]{2}{*}{ SNP } & \multicolumn{3}{|c|}{ Minor allele frequency } & \multicolumn{2}{|c|}{ P-value } & \multicolumn{2}{|c|}{ Permutation $p$-value } & \multicolumn{2}{|c|}{ Odds ratio $(95 \% \mathrm{Cl})$} \\
\hline & & $\begin{array}{c}\text { AR } \\
(n=128)\end{array}$ & $\begin{array}{c}\text { AS } \\
(n=|8|)\end{array}$ & $\begin{array}{c}\text { CTR } \\
(n=|5|)\end{array}$ & AR vs CTR & AS vs CTR & AR vs CTR & AS vs CTR & $A R$ vs CTR & AS vs CTR \\
\hline Rs2787094 & $\mathrm{G} / \mathrm{C}$ & 0.406 & 0.514 & 0.146 & $<0.0001$ & $<0.0001$ & $<0.0001$ & $<0.0001$ & $\begin{array}{c}0.25 \\
(0.17-0.37)\end{array}$ & $\begin{array}{c}0.16 \\
(0.11-0.24)\end{array}$ \\
\hline rs2280089 & $\mathrm{A} / \mathrm{G}$ & 0.231 & 0.102 & 0.136 & 0.0037 & 0.1812 & 0.0279 & & $\begin{array}{c}1.91 \\
(1.23-2.96)\end{array}$ & \\
\hline rs2280090 & $A / G$ & 0.094 & 0.158 & 0.04 & 0.0097 & $<0.0001$ & & $<0.0001$ & & $\begin{array}{c}4.52 \\
(2.37-8.59)\end{array}$ \\
\hline rs228009I & $\mathrm{G} / \mathrm{A}$ & 0.348 & 0.437 & 0.129 & $<0.0001$ & $<0.0001$ & $<0.0001$ & $<0.0001$ & $\begin{array}{c}0.28 \\
(0.18-0.42)\end{array}$ & $\begin{array}{c}0.19 \\
(0.13-0.28)\end{array}$ \\
\hline rs3918396 & $G / A$ & 0.109 & 0.113 & 0.136 & 0.3454 & 0.3802 & & & & \\
\hline rs612709 & $\mathrm{A} / \mathrm{G}$ & 0.063 & 0.121 & 0.036 & 0.1526 & $<0.0001$ & & 0.0016 & & $\begin{array}{c}3.66 \\
(1.86-7.22)\end{array}$ \\
\hline
\end{tabular}

miologic surveys presented at the European Respiratory Society Annual Congress (ERS) in 2007 supported the concept of 'one airway, one disease' $[24,25]$. In this context, we genotyped ADAM33 variants in AR cases and healthy individuals to evaluate the potential influences of ADAM33 gene polymorphisms on AR risk, and to determine whether ADAM33 is also the susceptible gene for AR. As expected, some significant associations were observed in AR patients. Although there are some differences between AR and AS in the statistical analysis results with respect to ADAM33 genetic susceptibility, polymorphisms of the ADAM33 gene may modify individual susceptibility to AR and AS in a Chinese Han population.

\section{Conclusion}

Our data suggest that the ADAM33 gene may be involved in the susceptibility to AR and AS in a Chinese Han population. The SNPs (V4 G/C, T+1 A/G, and T1 G/A) of the ADAM33 gene may play an important role in the susceptibility of AR disease, whereas ADAM33 V4 G/C, T2 A/G, T1 G/A, and Q-1A/G may participate in the susceptibility to AS. Considering that the limited sample size may produce relative risk estimates lacking adequate precision, extended analyses with a larger sample size should be carried out from different ethnic origins to further verify this association.

\section{Competing interests}

The authors declare that they have no competing interests.

\section{Authors' contributions}

D-J S performed the primer design. X-M ZH performed the PCR-RFLP experiments and wrote the drafts. HS contributed statistical analysis. F-ZH L and L-H J conceived of the study, and participated in its design and coordination and helped to draft the manuscript. J-ZH collected the patient and control blood samples. All authors read and approved the final manuscript.

\section{Acknowledgements}

This work was supported by the Project of Science Research Foundation of Heilongjiang (Grant No. II53 I I 45) and a grant from the Innovative Fund of Harbin Medical University Graduate Student (HCXB2007004). We thank all patients and healthy blood donors for providing blood samples. We are grateful for the collaboration received from the participating hospitals and their staff.

\section{References}

I. Management of allergic rhinitis and its impact on asthma: pocket guide. In Asthma workshop report in collaboration with the World Health Organization Geneva: WHO; 2001.

2. Asthma management handbook 2002. Melbourne: National Asthma Council Australia Ltd; 2002.

3. Corren J, Togias A, Bousquet J: Upper and lower respiratory disease. In Lung Biology in Health and Disease Volume 18I. New York: Marcel Dekker; 2003.

4. Togias A: Rhinitis and asthma: evidence for respiratory system integration. J Allergy Clin Immunol 2003, I I I: I I I I- I I 83.

5. Gaga M, Lambrou P, Papageorgiou N, Koulouris NG, Kosmas E, Fragakis S, Sofios C, Rasidakis A, Jordanoglou J: Eosinophils are a feature of upper and lower airway pathology in non-atopic asthma, irrespective of the presence of rhinitis. Clin Exp Allergy 2000, 30:663-669.

6. Rimmer J, Ruhno JW: Rhinitis and asthma: united airway disease. MJA 2006, I 85:565-57I.

7. Serrano C, Valero A, Picado C: Rhinitis and asthma: One airway, one disease. Arch Bronconeumol 2005, 41 :569-578.

8. van Eerdewegh P, Little RD, Dupuis J, Del Mastro RG, Falls K, Simon J, Torrey D, Pandit S, McKenny J, Braunschweiger K, Walsh A, Liu Z, Hayward B, Folz C, Manning SP, Bawa A, Saracino L, Thackston M, Benchekroun Y, Capparell N, Wang M, Adair R, Feng Y, Dubois J, FitzGerald MG, Huang H, Gibson R, Allen KM, Pedan A, Danzig MR, Umland SP, Egan RW, Cuss FM, Rorke S, Clough JB, Holloway JW, Holgate ST, Keith TP: Association of the ADAM33 gene with asthma and bronchial hyperresponsiveness. Nature 2002, 418:426-430.

9. Postma DS, Howard T: ADAM33 gene: confirming a gene without linkage. Clin Exp Allergy 2004, 34:I-3.

10. Howard TD, Postma DS, Jongepier H, Moore WC, Koppelman GH, Zheng SL, Xu J, Bleecker ER, Meyers DA: Association of a disintegrin and metalloprotease 33 (ADAM33) gene with asthma in ethnically diverse populations. J Allergy Clin Immunol 2003, I I 2:717-722.

II. Cheng L, Enomoto T, Hirota T, Shimizu M, Takahashi N, Akahoshi M, Matsuda A, Dake Y, Doi S, Enomoto K, Yamasaki A, Fukuda S, Mao $X Q$, Hopkin JM, Tamari M, Shirakawa T: Polymorphisms in ADAM 33 are associated with allergic rhinitis due to Japanese cedar pollen. Clin Exp Allergy 2004, 34:1 I 92-I20I.

12. Lee JH, Park HS, Park SW, Jang AS, Uh ST, Rhim T, Park CS, Hong SJ, Holgate ST, Holloway JW, Shin HD: ADAM33 polymorphism: 
association with bronchial hyper-responsiveness in Korean asthmatics. Clin Exp Allergy 2004, 34:860-865.

13. Noguchi E, Ohtsuki Y, Tokunaga K, Yamaoka-Sageshima M, Ichikawa $\mathrm{K}$, Aoki T, Shibasaki M, Arinami T: ADAM33 polymorphisms are associated with asthma susceptibility in a Japanese population. Clin Exp Allergy 2006, 36:602-608.

14. Takuro Sakagami, Nobuyoshi Jinnai, Toshiaki Nakajima, Takashi Sekigawa, Takashi Hasegawa, Eiichi Suzuki, Ituro Inoue, Fumitake Gejyo: ADAM33 polymorphisms are associated with aspirin-intolerant asthma in the Japanese population. J Hum Genet 2007, 52:66-72.

15. Hirota T, Hasegawa K, Obara K, Matsuda A, Akahoshi M, Nakashima K, Shirakawa T, Doi S, Fujita K, Suzuki Y, Nakamura Y, Tamari M: Association between ADAM33 polymorphisms and adult asthma in the Japanese Population. Clin Exp Allergy 2006, 36:884-891.

16. Lind DL, Choudhry S, Ung N, Ziv E, Avila PC, Salari K, Ha C, Lovins EG, Coyle NE, Nazario S, Casal J, Torres A, Rodriguez-Santana JR, Matallana H, Lilly CM, Salas J, Selman M, Boushey HA, Weiss ST, Chapela R, Ford JG, Rodriguez Cintron W, Silverman EK, Sheppard D, Kwok PY, Gonzalez Burchard E: ADAM33 is not associated with asthma in Puerto Rican or Mexican populations. Am J Respir Crit Care Med 2003, 168:1312-1316.

17. Raby BA, Silverman EK, Kwiatkowski DJ, Lange C, Lazarus R, Weiss ST: ADAM33 polymorphisms and phenotype associations in childhood asthma. J Allergy Clin Immunol 2004, I I 3: I07 I- 1078.

18. Werner M, Herbon N, Gohlke H, Altmüller J, Knapp M, Heinrich J, Wjst M: Asthma is associated with single-nucleotide polymorphisms in ADAM33. Clin Exp Allergy 2004, 34:26-3I.

19. Lind DL, Choudhry S, Ung N, Ziv E, Avila PC, Salari K, Coyle NE, Nazario S, Rodriguez-Santana JR, Salas J, Selman M, Boushey HA Weiss ST, Chapela R, Ford JG, Rodriguez-Cintron W, Silverman EK, Sheppard D, Kwok PY, Burchard EG: ADAM33 is not associated with asthma inPuerto Rican or Mexican populations. $\mathrm{Am}$ Respir Crit Care Med 2003, 168:1312-1316.

20. Leynaert B, Neukirch F, Demoly P, Bousquet J: Epidemiologic evidence for asthma and rhinitis comorbidity. J Allergy Clin Immunol 2000, 106:20I-205.

21. Beasley R, Keil U, von Mutius E, Pearce N: World wide variation in prevalence of symptoms of asthma, allergic rhinoconjunctivitis and atopic eczema: ISAAC. Lancet 1998, 35 I: I 225-I 232.

22. Leynaert B, Bousquet J, Neukirch C, Liard R, Neukirch F: Perennial rhinitis: an independent risk factor for asthma in nonatopic subjects: results from the European Community Respiratory Health Survey. J Allergy Clin Immunol 1999, 104:30 I-304.

23. Comorbid Asthma and Allergic Rhinitis: One Airway, One Disease. European Respiratory Society Annual Congress: 15-19 September 2007; Stockholm, Sweden .

24. Rha Y-H, Sohn B-K: Evaluation and control of allergic rhinitis in patients with asthma in Korea. Eur Respir J 2007, 30(Suppl 5 I):383.

25. Stojanovska $\vee$, Zafirovski $O$, Petrusevska : Allergic rhinitis in asthmatic children. Eur Respir J 2007, 30(SuppI 5 I):383.

\section{Pre-publication history}

The pre-publication history for this paper can be accessed here:

http://www.biomedcentral.com/1471-2350/9/82/prepub

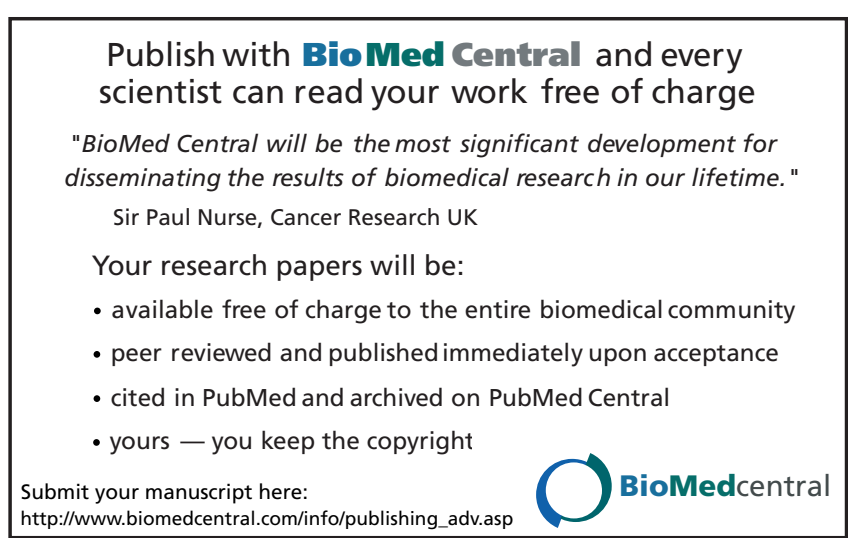

